\title{
An update on the current dental abnormalities of one-humped camel (Camelus dromedarius) in Maiduguri, Nigeria
}

\author{
A.Waziri ${ }^{1}$, M. B. Monguno ${ }^{1}$, E. Igwenagu ${ }^{1}$, I. Abdullahi ${ }^{1}$, S. U. Hassan ${ }^{1}$ \\ and I. O. Igbokwe ${ }^{1}$ \\ ${ }^{I}$ (Department of Veterinary Pathology, Faculty of veterinary Medicine, University of Maiduguri, Nigeria)
}

\begin{abstract}
Fifty four head samples of slaughtered one-humped camel (Camelus dromedarius) from Maiduguri Abattoir were used for the study. Out of this number, $33(61.12 \%)$ were found to have one or more lesions, while $20(38.88 \%)$ had no lesion. Broken tooth was found to have the highest prevalence of $20.75 \%$, while caries was found to have the lowest prevalence of 1.89\%. Among the 33 heads with lesions, 13 (24.53\%) were females and 20 (37.74\%) were males. Two (3.77\%) were between the ages of 1 and 3 years, 11 (20.75\%) were between the ages of 4 and 6 years and 20 (37.74\%) were 7 years and above. Sexual dimorphism and age difference were observed in the study, where broken tooth and dental calculi were seen more in females than in males and more in older camel than in younger ones.
\end{abstract}

Keywords: Camel, dental abnormalities, age specific, sex specific

\section{Introduction}

The one-humped camel (Camelus dromedarius) has some peculiarities of biochemical, anatomical and physiological differences from other animals due to its adaptation to arid condition and poor feeding resources [1]. It is an essential source of meat and milk in many developing countries in Asia and Africa.

Camels are selective feeders preferring halophyte plants and can feed on leaves of plants even if such plants have thorns, odours and secretions [2,3]. Owing to the importance of oral health, [5] and [6] have tried to establish the most common dental abnormalities encountered in these animals

The aim of this research is, therefore, to provide an update on the current dental abnormalities encountered in camel slaughtered at the Maiduguri metropolitan Abattoir.

\section{Material And Method}

A total of 54 camel heads of both sexes were examined for dental abnormalities in three visits to Maiduguri Metropolitan abattoir in May, 2015. The aging and sexing were conducted according to [2] and [4], respectively.

Gross dental abnormalities were noted and photographs taken using a digital camera (Sony, DSCW710). Simple percentage was used to summarize the data and Chi-square was used to analyse for significance among sex and age variations. P-value $<0.05$ was considered significant.

\section{Results}

Out of the 54 head samples, $33(61.11 \%)$ had dental lesions. Out of the 33, $20(37.74 \%)$ were male while $13(25.53 \%)$ were female. Two of them were between the ages of 1-3 years, 11 of them between the ages of 4-6 years and 20 were from 7 years and above. Variation in the occurrence of dental lesions according to sex and age are presented in Table 1.

Table 1: Sex and age specific prevalence of dental abnormalities of camels at slaughter in Maiduguri

\begin{tabular}{lllllll}
\hline \multirow{2}{*}{ Abnormality } & \multicolumn{2}{c}{ Sex } & \multicolumn{3}{c}{ Age (Years) } & \multirow{2}{*}{ Total (Prevalence, \%) } \\
\cline { 2 - 6 } & Male & Female & $1-3$ & $4-6$ & $>7$ & \\
\hline Calculi & 3 & 2 & 0 & 1 & 4 & $5(9.43)$ \\
Fluorosis & 1 & 2 & 0 & 1 & 2 & $3(5.66)$ \\
Caries & 1 & 0 & 0 & 1 & 0 & $1(1.89)$ \\
Enamel hypoplasia & 2 & 1 & 0 & 1 & 2 & $3(5.66)$ \\
Broken teeth & 7 & 4 & 0 & 4 & 7 & $11(20.75)$ \\
Transposition & 2 & 0 & 2 & 0 & 0 & $2(3.77)$ \\
Attrition & 1 & 2 & 0 & 1 & 2 & $3(5.66)$ \\
Crowding & 3 & 0 & 0 & 0 & 3 & $3(5.66)$ \\
Rotation & 0 & 2 & 0 & 2 & 0 & $2(3.77)$ \\
\hline Total number (prevalence, \%) & $20(37.74)$ & $13(24.53)$ & $2(3.77)$ & $11(20.75)$ & $20(37.74)$ & $33(61.12)$ \\
\hline
\end{tabular}




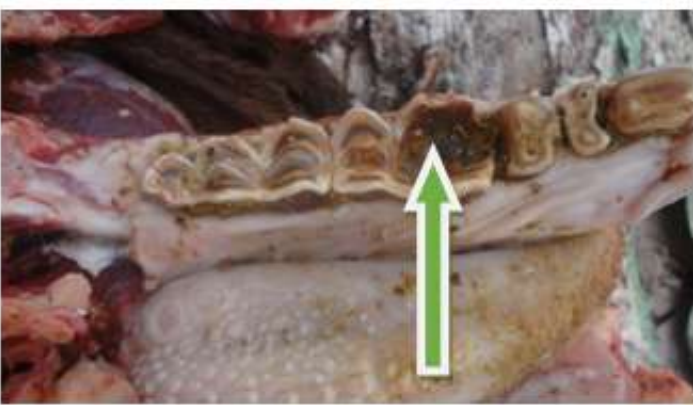

Figure 1. Lower dental of an a dult camel row showing attrition

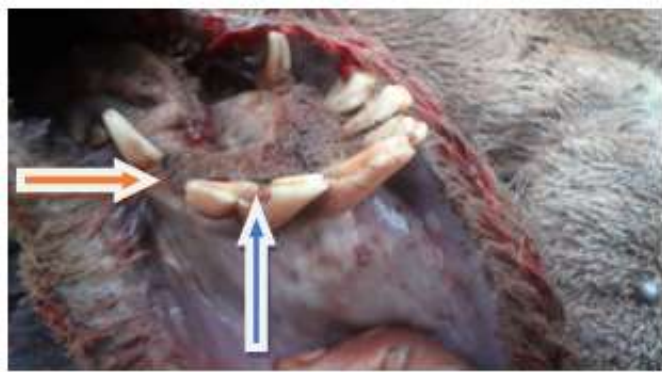

Figure 3. Lower dental fow of adult camel showing missing tooth (red arrow) and broken tooth (blue arrow)

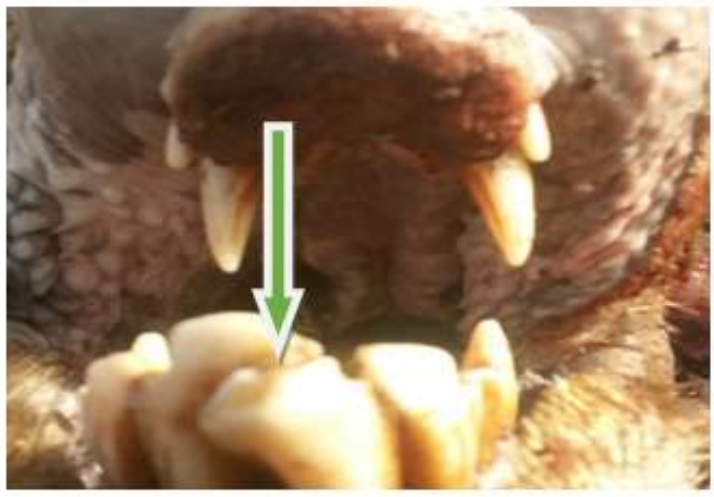

Figure 5. Lower dental row of a dult Camel showing transposition of the crown (incomplete transposition)

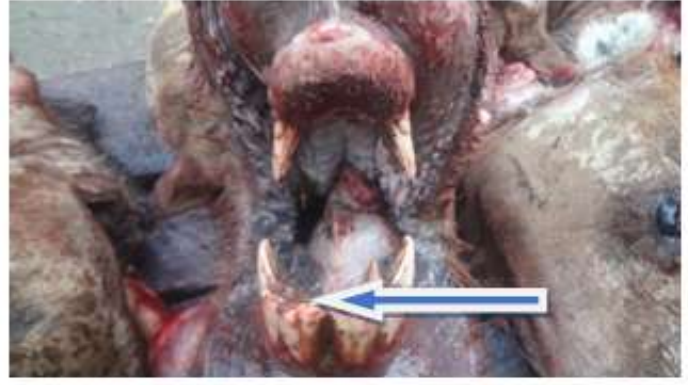

Figure 2. Lower dental row of a dult Camel showing a mineralised plaque a dhered to the tooth surface (dental calculi)

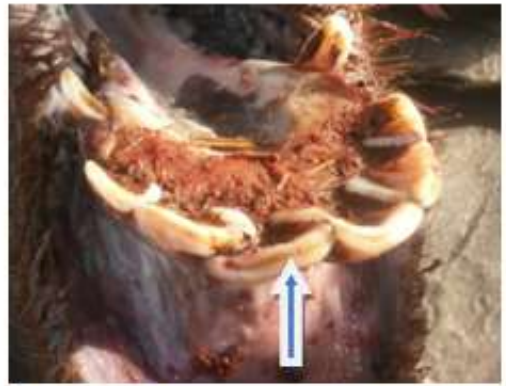

Fig. 4. Lower dental row of a dult Camel showing Enamel hypoplasia

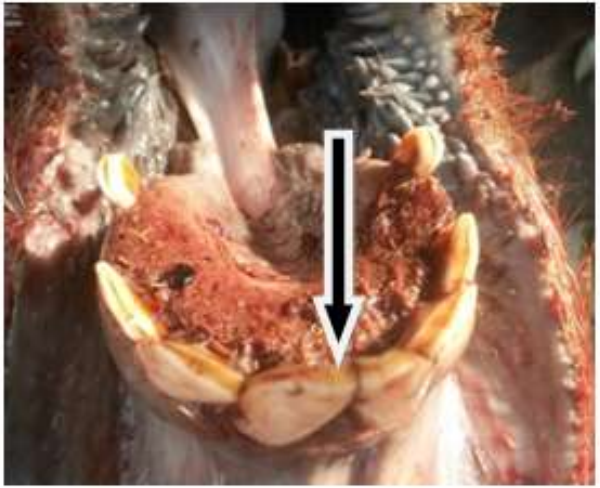

Figure 6. Lower dental row of a dult Camel showing brownish discoloration of the teeth (Flourosis)

\section{Discussion}

Poor oral/dental health has been found to be associated with poor prehension, improper mastication and early culling, resulting in unthriftiness, loss of condition and poor performance at work, decreased nursing, milk and meat production. This study showed that $33(61.12 \%)$ have one lesion or the other. The abnormalities found in order of decreasing prevalence were broken teeth $(20.75 \%)$, calculi $(9.43 \%)$, and caries $(1.89 \%)$. The findings on broken teeth in this study are similar to that of [5] who also reported highest prevalence $(7.6 \%)$ of broken teeth. This however disagrees with the report of [6], where the abnormalities with highest prevalence were attrition (100\%) and gingival recession (100\%). Broken teeth may occur in camels from natural habitats such as the desert where shrubs serve as the major roughage. The chewing of these tree branches with their spine and barks could be the major factor responsible [7]. The abnormality could also result from the restraint methods applied in work animal and probable pull force of working instruments. Furthermore, it is observed in this study that broken teeth is higher in male $20(37.74 \%)$, than in female $13(24.53 \%)$ and is more common in camel within the age range of 7 and above [20 (34.74.8\%)].

Dental calculi results from calcium salt that are deposited at a little quantity from time to time. The deposit will then gradually force the interdental space to widen more and more and this weakens the arcade [8]. 
From the result, calculi is higher in male than in female and it occurred more within the age range of 7 years and above.

From the study, the prevalence of dental fluorosis was 5.66\%. This is similar to the findings of [8]. Desert camels are least afflicted with osteo-dental fluorosis, and they can survive without need to drink water for more than 30 days. The severity of fluorosis is directly proportional to the frequency of fluoride intake. Another reason of camel being less susceptible to fluorosis might be because of high calcium and ascorbic acid (Vitamin C) in their diet which neutralizes the effect of excess fluoride content (8). The prevalence of dental caries is the least in the present study having the total of $1(1.89 \%)$ which occurred between the ages of 4-6 years. This can be caused by bacteria, which invade the pulp cavity and cause further destruction of organic matrix [7].

Sexual dimorphism was observed in the presentation of the abnormalities, where the prevalence was higher in males $(37.74 \%)$ than in females $(24.53 \%)$. This agrees with the report of [6], suggesting that the abnormalities progressed more in the males. Age differences were also observed in the study, as abnormalities were mostly seen in the age group of seven years and above (37.74\%).

\section{Conclusion}

This study gave an update on some dental abnormalities prevalent in slaughtered camel in Maiduguri. Broken-teeth have been found to be of highest prevalence. Poor performance from the animal may, therefore, be observed as a result of improper functioning of the teeth. Thus, paying more attention to Camel's oral health will be invaluable to the overall health and productivity of Camel population.

\section{Acknowledgements}

We would like to acknowledge the management of Maiduguri abattoir for providing us with the enabling environment to see the success of this research.

\section{References}

[1]. B. Faye, G. Saint-Martin, R. Cherrier, and Ali Ruffa, The influence of high dietary protein, energy and mineral intake on deficient young Camel: I. changes in metabolic profiles and growth performance, Comparative Biochemistry and Physioloogy, 102A,1992, 409-416.

[2]. R. T. Wilson, The Camel (Longman group limited, Essex, U. K. 1984) 158-159.

[3]. S. Ouajd, and B. Kamel, Physiological Particularities of Dromedary (Camelus dromedarius) and Experimental implication, Scandinavian journal of Laboratory Animal Science. 36, 2009, 19-29.

[4]. R. O. Ramadan, Surgery and Radiology of the Dromedary Camel. (Aljawad Printing Press, KSA, 1994). First edition. Pp 24-31.

[5]. C. A. Eze, S. S. Adamu, and M. M. Bukar, Studies on dentition and Oral disorders of Camels in Maiduguri Abbattoir. Tropical Animal Health and Production. Springer. 41(3), 2009 (published online 2012).

[6]. A. Yahaya, O. Femi-Akinlosotu, J. O. Olopade, and H. D. Kwari, A study of Dental abnormalities of Camels in Nigeria. Nigerian Veterinary Journal. 32(2): 2011, 92-96.

[7]. R. O. C. Kene, and E. A. Uwagie-Ero, Dental abnormalities of Nomadic Cattle of Nigeria. Tropical Veterinarian, 19, 2001, 191199

[8]. S. L. Choubisa, Flourotoxicosis in diverse species of domestic animals inhabiting areas with high fluoride in drinking waters of Rajasthan, India. Proc Natl Acad Sci India Sect B Biol Sci; 2013, 83(3), 317-21. 